\title{
Teoría del contrato, libertad y determinismo social: la posición incompatibilista
}

\author{
Mauricio Rengifo Gardeazabal ${ }^{*}$
}

Resumen: Rengifo se propone demostrar que los cambios históricos sociales producidos en el último siglo han afectado profundamente la noción tradicional de contrato. La existencia de condiciones generales de contratación y la aparición de las situaciones contractuales de hecho han recortado gravemente las libertades contractuales de conclusión y configuración. En efecto, el profesor Martín Hevia ha propuesto una nueva teoría del contrato fundada en la teoría de la justicia de John Rawls. Se trata de terminar una tarea inconclusa ya que Rawls solo se ocupó de la justicia en el marco de la estructura constitucional básica. Para llenar este vacío Hevia recurre a la filosofía kantiana del derecho, lo que según Rengifo, lo hace incurrir en una profunda inconsistencia. Palabras clave: contrato, justicia, autonomía.

\begin{abstract}
Rengifo proposes to demonstrate that the historical social changes produced in the last century have deeply affected the traditional notion of contract. The existence of general conditions of contracting and the appearance of the contractual situations of fact, they have cut away seriously the contractual freedoms of conclusion and configuration. In effect, the teacher Martin Hevia has proposed a new theory of the contract been founded on the theory of John Rawls's justice. It is a question of finishing an incomplete task since Rawls only dealt with the justice in the frame of the constitutional basic structure. To fill this emptiness he resorts to the Kantian philosophy of the right, which according to Rengifo, makes it incur a deep inconsistency.
\end{abstract}

Key words: contract, justice, autonomy.

* Profesor asociado de Derecho Civil, Universidad de los Andes, Bogotá, Colombia. Email: mrengifo@uniandes.edu.co 


\section{Introducción}

E1 profesor Martín Hevia ha propuesto una nueva teoría del contrato fundada en la teoría de la justicia de John Rawls. Se trata de terminar una tarea inconclusa ya que Rawls solo se ocupó de la justicia en el marco de la estructura constitucional básica. Para llenar este vacío Hevia recurre a la filosofía kantiana del derecho, que por obvias razones, es la filosofía que más parece ajustarse al constructivismo de Rawls. En este contexto, el contrato es una institución que permite a cada individuo razonable perseguir la realización de sus propias metas sin vulnerar la autonomía de los demás. Es una forma de interacción social basada en expectativas razonables.

Me temo que en la propuesta de Hevia hay una profunda inconsistencia. Por una parte, retoma algunas nociones básicas de la filosofía kantiana del derecho que están claramente comprometidas con la idea del contrato como manifestación de una voluntad libre, concepción claramente subjetivista, y por otra, rechaza esta tradición para defender una idea de contrato fundada en expectativas razonables, concepción claramente objetivista que poco o nada tiene que ver con la idea de una sociedad organizada como un reino de fines. La idea de expectativa razonable parece estar basada en el postulado de un hombre promedio, en el concepto utilitarista del observador imparcial que actúa con base en información más o menos completa. A menos que el universalismo kantiano y el consecuencialismo utilitario puedan combinarse en una nueva filosofía, sospecho que la concepción del contrato de Hevia se ha erigido sobre fundamentos poco seguros.

En cualquier caso, en este breve escrito no me propongo refutar directamente a Hevia. Más bien quisiera explorar un problema que, según creo, afecta no solo al profesor Hevia sino a todos los teóricos contemporáneos del contrato de origen kantiano. Este problema reside en el carácter histórico-social del concepto y, por ende, en la inevitable transformación de lo que entendemos por contrato. El olvido de estas transformaciones ha conducido a que los teóricos contemporáneos del contrato se extravíen en discusiones cuyos supuestos 
Teoría del contrato, libertad y determinismo social: la posición incompatibilista

han sido gravemente socavados por la aparición de nuevas formas de interacción social. En particular, sostengo que el contrato como institución social, si bien no ha muerto como lo han proclamado algunos, al menos sí ha cambiado tanto en algunos contextos que ha dejado de ser un instrumento al servicio de la libertad.

Recuérdese que la libertad contractual es de dos clases: la libertad de conclusión y la libertad de configuración. La primera consiste en el derecho a decidir si se celebra o no un contrato. El contrato se forma de un intercambio libre de oferta y aceptación. Pero el destinario de la oferta tiene la libertad de aceptarla o rechazarla. La segunda consiste en el derecho a definir el alcance y el contenido de las cláusulas contractuales. La libertad de configuración supone que la mayoría de las normas contractuales son de derecho dispositivo, lo cual significa que los ciudadanos tienen derecho a derogarlas mediante acuerdos particulares. Esto hace que buena parte de las normas civiles y comerciales tengan un carácter supletorio. Pues bien, todo parece indicar que las transformaciones históricas y sociales han limitado seriamente la libertad contractual.

Para probarlo me valdré de dos ejemplos clásicos. En primer lugar, explicaré la aparición de las denominadas 'condiciones generales de contratación' que han supuesto una profunda limitación a la idea de que el contrato permite alcanzar libremente las metas que se han propuesto individuos independientes y razonables. Sostengo que el uso extendido de las condiciones generales, si bien ha reducido significativamente los costos de la negociación en algunos sectores de la economía, también ha supuesto una seria limitación a la libertad de configuración contractual. Las condiciones generales han derogado el derecho dispositivo para sustituirlo por una reglamentación imperativa.

En segundo lugar, explicaré el surgimiento de las célebres 'situaciones contractuales de hecho', que suponen un concepto de contrato muy diferente del que se encuentra en la tradición. Las situaciones contractuales de hecho serían relaciones sociales necesarias en la que no se da la supuesta coordinación de intereses de hombres libres y razonables sino una limitación seria tanto de la libertad de conclusión como de la libertad de configuración contractual. Las situaciones 
contractuales de hecho han mutado el derecho dispositivo en derecho imperativo.

Espero que los ejemplos contribuyan a demostrar que ni el modelo kantiano ni el modelo supuestamente neokantiano de las expectativas razonables se adaptan claramente a las nuevas realidades contractuales.

Mi argumentación es en cierto sentido muy similar a la empleada por algunos filósofos en contra de la libertad de la voluntad. Si es verdad que las leyes físicas determinan el curso de los acontecimientos futuros, el libre albedrío es imposible. Algo similar es lo que he intentaré demostrar aquí. Si es verdad que muchas relaciones sociales se organizan por medio de las condiciones generales de contratación, la libertad de configuración contractual es imposible. Si es verdad que hay situaciones contractuales de hecho, la libertad de conclusión contractual es imposible. Si estoy en lo cierto, una concepción neokantiana del contrato deberá enfrentar estos problemas. Pero ¿qué son las condiciones generales de contratación y las situaciones contractuales de hecho?

\section{II.Las condiciones generales de contratación}

En lo que sigue, explicaré brevemente qué son las condiciones generales, para qué sirven, cómo se han regulado (haciendo especial énfasis en el principio de la incorporación, principal herramienta de control contra los abusos de las condiciones) y qué efectos producen. Finalmente, intentaré demostrar que el uso extendido de las condiciones generales no puede conciliarse fácilmente con la teoría del contrato de Hevia, ni con ninguna teoría kantiana o neokantiana sobre la materia.

\section{II.1. Concepto, naturaleza y función}

La práctica de fijar de antemano ciertas reglas para la asistencia a espectáculos masivos (teatro, ópera, salas de concierto) o para el acceso a servicios muy concurridos (clubes, bares, restaurantes, baños) parece 
ser el antecedente inmediato de las condiciones generales de contratación. Piénsese en un guardarropa ubicado en una sala de ópera a cuya entrada se pone un cartel con las reglas para dejar en depósito o retirar los abrigos. Un cartel de esta naturaleza normalmente establecería reglas sobre los abrigos abandonados, sobre la pérdida de bienes preciosos en los bolsillos, sobre la responsabilidad ante los eventuales daños derivados de la pérdida o deterioro de las prendas consignadas en el guardarropa. No hay duda de que el reglamento así diseñado tiene una gran utilidad práctica, al precaver las distintas eventualidades que pueden presentarse durante la prestación del servicio.

Con la aparición de los grandes servicios públicos (teléfono, acueducto, alcantarillado, iluminación, energía, transporte masivo) y el surgimiento de los servicios financieros modernos (banca, seguros, valores), se hizo necesario celebrar contratos en masa con los clientes y usuarios. En efecto, para atender rápida y eficazmente a una clientela numerosa, las grandes empresas empezaron a fijar unilateralmente algunas condiciones generales para la celebración de contratos: condiciones de pago a los proveedores o asalariados, condiciones de entrega para los clientes, plazos de entrega de los productos y servicios, lugar de cumplimiento, etc. Las condiciones generales se daban a conocer por medio de letreros en los locales, circulares y ejemplares impresos, reglamentos escritos al reverso de las constancias del servicio (boletos, fichas, tiquetes), formularios con cláusulas predispuestas, entre otros.

Las condiciones generales de contratación se extendieron rápidamente en todos los ámbitos del mercado. Como era de esperarse, muy pronto surgieron dudas sobre su naturaleza jurídica. Inicialmente se consideró que las condiciones generales constituían verdaderas normas jurídicas dado que habían sido pensadas como reglamentos que tenían aplicación para un número importante de ciudadanos. Un reglamento de transporte diseñado por una empresa pública o privada tendría validez para toda una ciudad. Cientos de miles de pasajeros tendrían que conducirse de acuerdo con los dictados de un empresario que había decidido por sí solo como debían ser las cosas. Surgió así la teoría normativa de las condiciones generales. Es preciso advertir que la teoría normativa no tenía pretensiones meramente académicas. Si las 
condiciones generales fuesen verdaderos reglamentos, actos administrativos de carácter general, su eventual control jurídico escaparía a la jurisdicción ordinaria.

Pero una reflexión más detenida nos revela que desde el punto de vista técnico, las condiciones generales no son normas del derecho objetivo. Para empezar, el empresario que las fija no tiene la autoridad que corresponde a los funcionarios o servidores públicos. E1 procedimiento para crear las condiciones no sigue las normas legales y administrativas previstas para leyes y decretos. Además, el control al que se someten es muy distinto del que rige para las verdaderas normas del ordenamiento jurídico. Es cierto que las condiciones son generales como lo son también las normas, pero esta generalidad es relativa, ya que solo aplica para quienes celebran los contratos en masa. Mientras las normas legales tienen fuerza vinculante desde que son promulgadas, las condiciones generales solo la adquieren con la celebración del contrato. También se ha dicho que las condiciones generales son costumbres normalizadoras del tráfico, es decir, costumbres que ordenan el mercado, como hacer fila en los bancos, esperar los trenes o buses en los paraderos, poner carteles con los precios de los productos, entre muchas otras. Sin embargo, para los usuarios de los servicios públicos o financieros, las condiciones generales no se entienden como costumbres, dado que su contenido es más bien técnico y específico: hacer los pagos en ciertos horarios, realizar las entregas en determinados lugares, presentar ciertas constancias, etcétera. Las costumbres están grabadas en la mente de los seres humanos, son una cuestión de hábito, mientras que las condiciones generales tienen que informarse debidamente para que puedan ser conocidas y obedecidas por los ciudadanos. Lo que sí resulta ser una costumbre es que en ciertos negocios se usen condiciones generales (por ejemplo, los negocios que emplean taquillas, ventanillas de atención al público, cajas registradoras).

La interpretación normativa ha sido sustituida en la mayoría de países por la teoría contractualista. De acuerdo con esta teoría, las condiciones generales hacen parte del derecho privado de los contratos. Se trata de cláusulas contractuales predispuestas por una de las partes 
con dos propósitos fundamentales: primero, hacer parte de una pluralidad de contratos futuros, lo cual ahorrará un tiempo valioso para las partes, más interesadas en la pronta prestación del servicio que en el conocimiento de sus detalles concretos, y, segundo, derogar el derecho dispositivo (o derecho supletorio) para sustituirlo por normas más acordes con las necesidades del negocio.

Quizás la mejor aproximación al concepto de condiciones generales la encontramos en el Derecho civil alemán. El Código Civil Alemán ${ }^{1}$ (en adelante BGB) define con gran acierto las condiciones generales de contratación como 'todas las cláusulas contractuales predispuestas para una pluralidad de contratos, que una parte contractual presenta a la otra parte en la conclusión del contrato'2 ${ }^{2}$ Para que un conjunto de cláusulas sean condiciones generales es necesario que se den dos requisitos: existencia de cláusulas predispuestas (principio de predisposición) y destinación para una pluralidad de contratos (principio de generalidad). El principio de predisposición establece que las condiciones deben haber sido concebidas y redactas por una de las partes. Si llegare a ocurrir que las cláusulas han sido negociadas por las dos partes, obviamente, no estamos ante condiciones generales. El principio de generalidad señala que solo son condiciones generales las cláusulas que, tras haber sido predispuestas por una de las partes, serán empleadas en la conclusión de un número indefinido de contratos. Por tanto, no hay condiciones generales cuando se ha diseñado un formulario que solo será utilizado eventualmente con unos cuantos clientes.

Pero hay más principios a tener en cuenta. Para que un conjunto dado de cláusulas predispuestas sean condiciones generales no es necesario que hagan parte del documento contractual principal (principio de la independencia). Son condiciones a pesar de estar en otros documentos, trátese de formularios separados o anexos, carteles, tiquets, circulares, volantes, etc. Tampoco es necesario que tengan una extensión determinada, por muy corta o muy larga que sea (principio

1 En alemán Bürgerliches Gesetzbuch.

2 Código civil alemán. Art. 305. 
de la extensión). Un libro de reglamentos o un simple cartel con dos o tres reglas pueden constituir condiciones generales. Asimismo, es irrelevante la forma del contrato, trátese de contratos verbales o escritos, consensuales, solemnes o reales, siempre pueden concurrir las condiciones generales (principio de la forma). Finalmente, es indiferente la forma de redacción, si se presenta como una advertencia al público, como información importante o de interés, como reglamento técnico o como un recordatorio (principio de la equivalencia).

La rápida expansión de las condiciones generales de contratación en el mundo de los negocios se debe a su gran utilidad práctica. Para empezar, las condiciones sirven para unificar los productos contractuales en un solo modelo, lo cual contribuye a simplificar las relaciones con un número elevado de clientes. Además, las condiciones generales sirven para estandarizar los productos y servicios de la empresa al unificar los plazos de entrega, las condiciones de pago y suministro, las garantías ofrecidas, las reglas de responsabilidad, los términos para presentar reclamaciones, etc. Las condiciones generales también pueden servir para adaptar las normas de derecho dispositivo a las características especiales de cada negocio. En muchas ocasiones, las normas dispositivas previstas por la legislación civil son demasiado abstractas y es necesario apartarse de sus lineamientos. Hay que recordar que los particulares tienen libertad para configurar sus propios contratos mediante la derogatoria del derecho dispositivo. Piénsese, a manera de ejemplo, en una nueva modalidad de contrato fiduciario cuyo régimen de responsabilidad debe orientarse por parámetros menos exigentes a los concebidos por la ley. E igualmente, imagínese un nuevo tipo de contrato de transporte combinado en el que resulta indispensable establecer la responsabilidad del organizador del viaje. En el mismo sentido, el predisponente sabe que las condiciones generales pueden servir para exigir al público garantías suplementarias en operaciones de crédito (pactos de reserva de dominio, retención de los bienes del deudor) o para establecer un régimen de garantías que sea menos oneroso para la empresa. 
Teoría del contrato, libertad y determinismo social: la posición incompatibilista

\section{II.2. La regulación de las condiciones generales}

La rápida difusión de las condiciones generales en la contratación moderna no estuvo exenta de graves reparos e inconvenientes. Es apenas natural que algunas empresas quisieran sacar provecho de la reglamentación unilateral de los contratos. Aparecieron entonces las condiciones generales que vulneraban los derechos fundamentales de una de las partes o que reducían o eliminaban completamente las responsabilidades del predisponente. En lo que sigue examinaremos las diferentes justificaciones de la intervención judicial o administrativa en la presentación de condiciones generales.

\section{II.2.1. Fundamento de la regulación}

El uso de condiciones generales puede resultar particularmente lesivo para la libertad de contratación. En muchas ocasiones, las grandes empresas logran controlar porciones significativas del mercado, instaurando un poder monopólico. Cuando una empresa poderosa fija condiciones generales para el público, los ciudadanos no tienen más opción que someterse a las reglamentaciones ante la perspectiva de quedarse sin el servicio. No hay otras empresas a las que pueda acudir en busca de condiciones más favorables. En tales circunstancias las compañías más poderosas pueden aprovecharse de su enorme poder para diseñar cláusulas abusivas, que prácticamente dejen al cliente sin acciones para reclamar sus derechos.

Los abusos en las condiciones generales también pueden presentarse en mercados competitivos. El simple hecho de que los servicios ofrecidos por las empresas tengan un carácter técnico y que los clientes no tengan ni el tiempo ni la formación para entenderlos, se presta para que el predisponente defraude al cliente con cláusulas leoninas. Un buen ejemplo de esta situación la encontramos en el ramo de los seguros. Las condiciones generales que suelen acompañar a las pólizas de seguros son tan complejas que una recta comprensión de sus disposiciones requiere de prolongados estudios. Infortunadamente, algunas empresas se valen de la dificultad de la materia para incluir cláusulas abusivas que hacen prácticamente imposible ganar una reclamación. 
La famosa letra menuda de los contratos del sector financiero y asegurador se presta para este tipo de prácticas contrarias a la buena fe.

Las condiciones generales derogan el derecho dispositivo contenido en los códigos civiles. Esta derogación hace parte de la libertad de configuración contractual y se justifica por la necesidad de adaptar los contratos a las particularidades de cada ramo de los negocios. Sin embargo, la libertad de configuración se usa sin que exista una justificación legítima. En muchas ocasiones, la desviación no tiene otro propósito que someter a la parte más débil a los dictados de los más fuertes. La libertad de configuración se usa entonces en forma abusiva, porque pretende dejar todas las ventajas para una de las partes y todas las cargas para la otra.

Pero la problemática que plantean las condiciones generales no depende únicamente de la existencia de desigualdades económicas en el mercado. Tampoco se explica por los desiguales conocimientos de las partes sobre el objeto del negocio. El problema también es de tiempo. Los consumidores y usuarios simplemente no tienen el tiempo para sentarse a estudiar las condiciones generales. Las empresas tampoco disponen del personal suficiente para diseñar contratos a la medida de cada cliente. La urgencia de celebrar un número masivo de contratos impide un diálogo prolongado entre las partes. Exigir negociaciones detalladas y contratos a la medida supone costos prohibitivos para ambas partes, siendo necesario recurrir a los formularios y a las cláusulas predispuestas. Por razones de eficiencia se hace indispensable el uso de condiciones generales. Naturalmente, por tratarse de condiciones prefijadas por una sola de las partes, se pierde lo que los juristas alemanes denominan el 'control de exactitud' propio de los contratos que resultan de una verdadera negociación. Cuando dos partes realmente participan en una negociación contractual tienen la oportunidad de controlar la redacción de las cláusulas, revisando que realmente se ajusten a sus deseos e intereses. Cuando hay condiciones generales, los tratos preliminares se reducen al mínimo, no hay control de exactitud, lo cual hace que la brecha entre la declaración y la voluntad se amplíe considerablemente. 
Teoría del contrato, libertad y determinismo social: la posición incompatibilista

En conclusión, existen buenas razones para pensar que las condiciones generales de contratación deben ser reguladas por las autoridades estatales. La desigualdad de las partes por motivos económicos (monopolios, poder dominante en el mercado) o informacionales (información técnica o privilegiada que solo posee el predisponente) hace necesario la protección de la parte más débil. Pero también, a causa de los altísimos costos de transacción que supondría operar con contratos a la medida de las partes, se hace imposible que las partes expongan sus necesidades y construyan acuerdos totalmente satisfactorios para sus intereses. La falta de un control de exactitud expone a los clientes a todo tipo de injusticias (cláusulas de exoneración de responsabilidad, períodos de sospecha, prescripciones muy largas, permisos para ejercer los derechos contractuales, etc.). La urgencia en la conclusión del contrato hace que las partes renuncien a investigar condiciones más favorables o propuestas alternativas. En el mundo de los contratos en masa el mercado es imperfecto, así que corresponde a los jueces y a los funcionarios públicos corregir sus fallas.

El uso de condiciones generales no solo es frecuente entre empresarios y consumidores, entre fuertes y débiles, sino también entre los mismos empresarios y comerciantes. La urgencia de realizar transacciones comerciales sin recurrir a largas negociaciones explica esta práctica. Como bien podrá suponerse, también entre empresarios es necesaria la regulación de las condiciones generales de contratación. El fundamento para esta intervención no es tanto la desigualdad de las partes, no tan frecuente entre empresas, como la falta de un control de exactitud, ya que el clausulado no se discute en tratos preliminares.

La doctrina civil francesa ha reconocido la aparición de contratos sometidos a condiciones generales. Raymond Saleilles, padre del derecho civil europeo, en su célebre obra De la declaración de voluntad (1901) denominó al nuevo fenómeno jurídico "contratos de adhesión"3. Años más tarde, Louis Josserand", en su Curso de derecho

3 Saleilles, R., De la déclaration de volonté, Paris, Librarie Générale du Droit et de Jurisprudence, 1929. Art. 133. 89 y 90, págs. 229-230.

4 Josserand, L., Curso de derecho positivo civil francés, Buenos Aires, Bosch, 1950. 
positivo civil francés (1939) clasificó los contratos en dos grandes categorías: contratos de adhesión y contratos paritarios - gré à gré-. Al respecto escribe:

En el tipo tradicional y clásico del contrato, se pesan, discuten y establecen en el momento del trato las cláusulas y las condiciones, y a esta tarea ambas partes cooperan igual y libremente. Este tipo no ha desaparecido completamente; lo volvemos a encontrar en la venta de inmuebles, en la venta de géneros en un mercado. Se entabla una discusión, más o menos larga, más o menos animada; se disputa palmo a palmo el terreno; es posible un regateo; las cosas se hacen con igualdad; no parece que una de las partes imponga su ley a la otra; el contrato es verdaderamente la obra de dos voluntades; se prepara y se termina de igual a igual; se podría calificar de contrato paritario. Al lado de este tipo de contrato, en que triunfa la autonomía de la voluntad, ha hecho su aparición en el siglo último, y ha tenido una rápida fortuna, otro contrato que excluye toda discusión, todo regateo entre las partes. Se presenta por una de ellas un proyecto de convención; se ofrece este hecho al público, al primero que llega; cualquiera puede acogerse a él, pero con la condición de aceptarlo tal cual es: tomarlo o dejarlo. (...) En estas condiciones, no es igual la situación entre las partes que desempeñan papeles de importancia desigual; una de ellas hace un reglamento, una redacción por anticipado, emite una tarifa, mientras que la otra se limita a acogerse a ella, a aceptar sus disposiciones sin tener la posibilidad de discutirlas; se limita a dar su adhesión, o, más correctamente, se trata de contratos por adhesión $n^{5}$.

En realidad, la distinción debería plantearse entre contratos de libre discusión y contratos de adhesión. Recuérdese que las condiciones generales también se pueden fijar entre partes iguales, como sucede entre empresarios. Nótese que bajo esta concepción, un contrato puede ser de adhesión sin que contenga condiciones generales. Basta con que

5 Josserand, L., Curso de derecho positivo civil francés, Buenos Aires, Bosch, 1950. 
Teoría del contrato, libertad y determinismo social: la posición incompatibilista

una parte haya predispuesto las cláusulas pensando en usarlas en un solo contrato particular y no en una pluralidad de ellos. Esta distinción es importante porque las cláusulas abusivas pueden darse tanto en condiciones generales como en contratos de adhesión particulares.

\section{II.2.2. Desarrollo de la regulación}

La regulación de las condiciones generales de contratación se remonta al siglo diecinueve en Alemania. La teoría suscitada por la aparición de la contratación en masa es sumamente vasta. Podemos distinguir al menos cinco etapas en su desarrollo. En la primera etapa, los tribunales intervienen para corregir algunos abusos en la redacción de las llamadas condiciones generales (Allgemeinen Geschäftsbedingungen). La intervención ocurre con frecuencia cuando las condiciones generales han sustituido el ius dispositivum por normas que parecen favorecer exclusivamente los intereses del predisponente. Sin embargo, en los inicios, la intervención de los tribunales se restringe a los casos de oscuridad de las cláusulas. Frente a las disposiciones oscuras los jueces se valen del principio general de la ambiguitas contra stipulatorem. De acuerdo con este principio, la cláusula ambigua o indeterminada debe interpretarse contra aquel que la redactó. La acción de los jueces, aunque oportuna, es todavía muy tímida. La segunda etapa, empieza en 1906 cuando el tribunal supremo del Reich alemán decide declarar la nulidad de todas aquellas cláusulas de las condiciones que sean el resultado de un abuso de poder por parte de empresas que ocupen una posición dominante en el mercado. El fundamento de esta intervención es el régimen de la licitud del objeto del contrato. Al respecto dispone el BGB:

Art. 138. Un negocio jurídico que atente contra las buenas costumbres es nulo. Es en especial nulo un negocio jurídico por el cual alguien, explotando la necesidad, la ligereza o la inexperiencia de otro, se haga prometer o se procure para sí o para un tercero, a cambio de una prestación, unas ventajas patrimoniales que sobrepasen de tal forma el valor de la 
prestación, que según las circunstancias estén en manifiesta desproporción con dicha prestación.

Como puede apreciarse, la tendencia jurisprudencial de aquel entonces fundamentaba las decisiones sobre la idea de desigualdad económica de las partes y discrepancia entre las condiciones generales y las buenas costumbres. La tercera etapa se inaugura con los pronunciamientos del Tribunal Federal de mediados de los años cincuenta. A partir de esta época, el fundamento de las decisiones cambia y el acento pasa de las normas sobre ilicitud del objeto al principio de la buena fe. En adelante, se entendió que los abusos en las condiciones generales no siempre estaban asociados a la desigualdad de las partes sino al hecho de que habían sido fijadas unilateralmente, sin la discusión propia de los tratos preliminares. El fundamento normativo de la nueva jurisprudencia estaba en el principio de la buena fe, según el cual 'el deudor está obligado a cumplir la prestación según las exigencias de la buena fe conforme a los usos del tráfico' ${ }^{6}$. Para que los jueces declararan la nulidad de una cláusula era necesario que se encontrara una desviación injustificada del derecho dispositivo o una restricción a los derechos y deberes fundamentales del contrato. La cuarta etapa, surge con la expedición de la ley sobre condiciones generales de contratación (Gesetz zur Regelung des Rechts der Allgemeinen Geschäftsbedingungen) de 1976, más conocida como la AGBG. Esta ley recoge los principios y reglas establecidos por la jurisprudencia alemana a lo largo de un siglo. Es también la ley que ha servido de modelo básico y fuente de inspiración para muchas otras leyes sobre la materia tanto a nivel europeo como latinoamericano. La principal característica de esta ley está en su marcada orientación hacia la protección de las partes que no han tenido la oportunidad de conocer y discutir el contenido de las cláusulas. Aunque la ley no usaba la categoría concreta, es clara también su pretensión de defender al consumidor, entendido como aquella persona que realiza una transacción por fuera de su ámbito profesional. La AGBG hace parte de toda una serie de leyes de protección a los consumidores en el contexto de la

${ }^{6}$ BGB. Art. 242. 
creación de un mercado único europeo. El problema con estas leyes es que no estaban integradas en el derecho contractual clásico y resultaban carentes de sistematicidad en el cuerpo del derecho civil alemán. La última etapa, inaugurada en los años noventa, precisamente es una respuesta a la problemática de conciliar el derecho de las obligaciones tradicionales con las normas de protección de los consumidores. Esta problemática parece haberse resuelto con la ley de reforma al derecho de las obligaciones del 2002. En esta reforma finalmente se incorporaron al BGB, en un interesante equilibrio, las leyes de protección de los consumidores, incluida la AGBG.

En el resto de Europa, la positivización de la regulación sobre las condiciones generales tiene como principal antecedente el Código Civil italiano. En efecto, el Codice trae dos artículos (1341 y 1342) que desarrollan principios parecidos al Derecho civil alemán. Pero ha sido la Unión Europea la que más ha hecho por impulsar el tema en la región. Con la expedición de la directiva 93/13 del Consejo de la Comunidad Económica Europea (en adelante CEE) de 5 de abril de 1993 se dio impulso a la regulación generalizada de las condiciones generales. En España, por ejemplo, se promulgó la ley 7 de 1998 sobre condiciones generales. En Francia se promulgó toda una regulación completa sobre la materia en el Código del consumo. Se trata de un régimen relativamente uniforme destinado a la protección de los consumidores e incluso de los empresarios que negocian entre sí. La regulación interviene en forma decisiva en la etapa de formación del consentimiento.

\section{II.3. El principio de la incorporación}

La protección de los adherentes a contratos sometidos a condiciones generales se logra mediante una serie de reglas básicas que regulan su incorporación al cuerpo del contrato. Recuérdese que no es necesario que el contrato contenga el tenor literal de las condiciones o un resumen de las mismas. Si el contrato ya contiene las condiciones, su vigencia depende de la sola aceptación por parte del adherente. E1 problema se plantea, como es usual en los negocios masivos, cuando 
las condiciones están en un documento separado del contrato. En esta situación, el principio fundamental establece que las condiciones generales solo hacen parte del contrato si y solo si el predisponente ha informado al adherente sobre la existencia de las condiciones (principio de la incorporación). Sin la indicación de su existencia, la aceptación no puede extenderse a las condiciones generales dado que el destinatario de la propuesta no habría tenido la oportunidad de conocerlas. En consecuencia, el contenido del contrato se limitaría al clausulado realmente ofrecido al destinatario, y, en caso de lagunas o vacíos, se aplicaría el derecho dispositivo.

En el sistema alemán, la incorporación tiene requisitos diferentes según se trate de contratos escritos o verbales. En los contratos escritos, se requiere que en el documento conste una cláusula expresa en la que se informe de la existencia de las condiciones generales, circunstancia que el destinatario debe aceptar con su firma (BGB art. 305). Además, es preciso que el predisponente, como paso previo a la celebración del contrato, entregue un ejemplar que contenga las condiciones. Esta hipótesis se conoce como incorporación expresa. En la incorporación expresa no es necesario que el adherente las haya leído o las conozca de hecho, cosa por lo demás difícil cuando se trata de un reglamento extenso y de gran complejidad técnica (como sucede con muchos de ellos). Es suficiente con que el adherente tenga apenas la posibilidad de conocerlas. En los contratos verbales, si llegare a existir una dificultad práctica para mencionarlas, basta con que el predisponente anuncie la existencia de condiciones generales por cualquier medio que garantice conocerlas (BGB art. 305). Por ejemplo, mediante la ubicación de carteles en un lugar visible de las oficinas, por medio de su inserción en la documentación anexa al contrato verbal, e incluso, a través de la entrega de un libro explicativo de las mismas, etc. Esta segunda hipótesis se conoce como incorporación tácita. Las dificultades prácticas pueden resultar de la necesidad de atender rápidamente a una clientela numerosa en cajas, taquillas, etc. En caso de que el adherente tenga alguna discapacidad física (ceguera, sordera, etc.) la conducta desplegada por el predisponente deberá adecuarse a esta circunstancia. 
Teoría del contrato, libertad y determinismo social: la posición incompatibilista

En el comercio internacional se admiten circunstancias que suplen la necesidad de informar sobre la existencia de las condiciones generales. Se trata de supuestos de incorporación tácita que tienen su fundamento en la lex mercatoria. Por ejemplo, en ciertas compraventas internacionales se admite que ciertas condiciones de venta o de compra hacen parte del contrato a pesar de que no hay cláusula que mencione su existencia. Un uso o costumbre reguladora del tráfico es suficiente para que ocurra la incorporación tácita. Igualmente, cuando dos comerciantes han tenido tratos frecuentes, se admite que las condiciones de venta o de compra predispuestas por las partes hacen parte del contrato sin necesidad de la mención expresa en los contratos futuros. Nadie podría alegar la no incorporación cuando en los negocios pasados se había admitido la vigencia de las condiciones generales. Los supuestos de incorporación tácita basados en costumbres mercantiles o en negocios precedentes son de dudosa aceptación en las legislaciones internas de los países. La protección de los consumidores exige que solo se permita la incorporación mediante información expresa o, al menos, mediante avisos o carteles claramente visibles.

En el sistema español se exigen requisitos similares. En los contratos escritos, para que la incorporación se produzca es necesario que el predisponente informe al adherente sobre su presencia y le entregue un ejemplar. Acto seguido, es preciso que el adherente manifieste con su firma su aceptación de las condiciones (Incorporación expresa. Ley 7/1998. Art 5. Núm. 1). En los contratos verbales, al igual que en el sistema alemán, es suficiente con que el predisponente las anuncie por cualquier medio que garantice que el adherente conocerá su existencia (Incorporación tácita. Ley 7/1998. Art. 5. Núm. 2).

La incorporación de las condiciones generales en el contrato no siempre es automática. En algunos países, se exige que las condiciones no contengan cláusulas sorpresivas. Para entender este punto es preciso recordar que la incorporación no exige que el adherente conozca efectivamente el contenido de las condiciones generales: es suficiente con que tenga la posibilidad de conocerlas. Esta regla vale tanto para las condiciones presentes en el contrato como para las condiciones elaboradas en documento separado. Ciertamente, exigir un conocimiento 
real y efectivo de las cláusulas le restaría toda utilidad a la predisposición de condiciones generales. Pero también es cierto que muchísimos adherentes no aprovechan la oportunidad que se les brinda para estudiar las condiciones. De hecho, muchos de ellos solo vienen a leer el clausulado cuando se ha presentado alguna inconformidad con la transacción. Esta situación se presta nuevamente para abusos por parte del predisponente.

Para remediar esta situación, algunos países europeos como Alemania o Italia han establecido una regla adicional sobre cláusulas sorpresivas. De acuerdo con esta regla, acogida por el derecho civil alemán, quien adhiere a un contrato no lo hace respecto de las cláusulas que sean consideradas sorpresivas (BGB art. 305 c). Son cláusulas sorpresivas aquellas que de acuerdo con el contenido del contrato o con su redacción son tan inusuales que el adherente no podía razonablemente contar con ellas. Hay muchos casos sobre cláusulas sorpresivas por el contenido del contrato. Por ejemplo, en un contrato de seguros contra incendios sería sorpresiva una cláusula que excluyera como riesgo asegurable el fuego hostil y se limitara a asegurar los daños provenientes del humo o del calor intenso. Igualmente, en un contrato de transporte de cosas sería sorpresiva una cláusula que negara todo tipo de responsabilidad proveniente de la pérdida o avería de las mercancías. En los paquetes turísticos, sería sorpresiva una cláusula que eximiera de toda responsabilidad por los servicios ofrecidos en el viaje. Las cláusulas sorpresivas por la redacción también son frecuentes, por ejemplo, cuando el predisponente emplea cláusulas con letra pequeña, o simplemente cuando redacta el reglamento con cláusulas oscuras o ambiguas. El uso de términos técnicos o de idiomas desconocidos puede también confundir al adherente. La solución en estos casos es entonces la no incorporación. Pero incluso si la incorporación estuviese probada, el adherente todavía podría recurrir al principio de la interpretación contra proferente según el cual, las cláusulas ambiguas se interpretan contra aquel que las redactó.

Sin lugar a dudas, la regla sobre cláusulas sorpresivas es un desarrollo de la teoría de las expectativas razonables, tan importante para el profesor Hevia. De acuerdo con esta teoría, quien adhiere a 
un contrato con condiciones generales solo extiende su aceptación a aquellas cláusulas que según las expectativas razonables de un hombre promedio cabe esperar en el contrato celebrado. Esta garantía permite al juez, en caso de litigio, excluir del contenido del contrato aquellas cláusulas de las condiciones generales que consagren disposiciones que nadie habría aceptado de haber tenido la oportunidad de conocerlas o negociarlas.

Cuando el principio de la incorporación no se cumple, el contrato entre el proponente y el aceptante de todas maneras se forma, solo que las condiciones generales no tendrán ninguna eficacia jurídica. En caso de presentarse lagunas o vacíos en el régimen del contrato, simplemente se aplicará el derecho dispositivo. Sin embargo, si la aplicación del derecho dispositivo hace sumamente difícil exigir el cumplimiento del contrato a una de las partes, se considerará ineficaz (BGB art. 306).

En materia de comercio internacional los principios de Unidroit también regulan las condiciones generales, denominadas en este contexto 'cláusulas estándar'. Los principios de Roma definen cláusulas estándar como 'aquellas preparadas con antelación por una de las partes para su uso general y repetido y que son utilizadas, de hecho, sin ser negociadas con la otra parte' (art. 2. 21). Además, se reitera que las cláusulas que han sido negociadas por ambas partes no son cláusulas estándar. En una interesante norma se regula lo que sucede cuando un mismo tema ha sido regulado por dos cláusulas distintas, una de ellas redactada por ambas partes, y la otra, predispuesta en un formulario. El artículo 2.21 dispone que 'en caso de contradicción entre una cláusula estándar y una que no lo sea, prevalecerá esta última'. Los principios de Roma no contienen el principio de incorporación exigido en la mayor parte de las leyes europeas, quizás porque en el comercio internacional hay mayor flexibilidad respecto de las condiciones. Sin embargo, sí consagra toda una disposición sobre estipulaciones sorpresivas. En efecto, su artículo 2.20 establece que '(1) carecerá de eficacia toda estipulación incorporada en cláusulas estándar cuyo contenido o redacción, material o formal, no fuese razonablemente previsible por la otra parte, salvo que dicha parte la acepte 
expresamente. (2) Para determinar la existencia de dicha estipulación, se tendrá en cuenta su contenido, lenguaje y presentación'. Nótese que la solución de los principios de Roma es distinta a la concebida en el Derecho civil europeo. Mientras que en las normas europeas las cláusulas sorpresivas no hacen parte del contrato por contravenir las expectativas razonables, en los principios se declaran ineficaces.

\section{II.4. Efectos jurídicos}

La incorporación de las condiciones generales en los contratos tiene dos efectos importantes. Primero, las cláusulas adquieren plena vigencia para las partes de acuerdo con el principio de normatividad del contrato. Segundo, el contrato con condiciones generales no debe contener cláusulas abusivas so pena de nulidad, y en especial, aquellas que están expresamente prohibidas por la ley. Sobre este punto es preciso realizar una breve digresión sobre el concepto de 'cláusulas abusivas'. Naturalmente, se puede hablar de cláusulas abusivas en un sentido amplio para hacer referencia a cualquier cláusula injusta o contraria a la buena fe, como puede serlo una cláusula leonina en un contrato de sociedad. Sin embargo, el concepto de cláusula abusiva ha adquirido un sentido más técnico, que es el que predomina actualmente en la doctrina civil. Dicho concepto técnico está estrechamente relacionado con la protección de los consumidores en los contratos con cláusulas predispuestas.

De acuerdo con la directiva 93/13/CEE de 1993, para que una cláusula sea abusiva deben cumplirse dos requisitos: (1) debe tratarse de una cláusula predispuesta sea en condiciones generales de contratación o en contratos de adhesión particulares; (2) pese a las exigencias de la buena fe, deben causar, en detrimento del consumidor, un desequilibrio importante entre los derechos y obligaciones de las partes que se derivan del contrato. El primer requisito establece que solo las cláusulas que no han sido negociadas por ambas partes pueden ser abusivas. Por el contrario, las que sí han sido negociadas y convenidas por ambas partes no pueden ser tenidas como tales. El segundo requisito señala que las cláusulas deben causar un desequilibrio importante en los 
derechos y obligaciones del consumidor. El concepto central aquí es el de 'desequilibrio contractual importante'. Hay desequilibrio contractual importante cuando una de las partes goza de pocos derechos y contrae muchas obligaciones en comparación con la situación de su contraparte. Si el adherente a un contrato considera que este contiene cláusulas abusivas tiene derecho a solicitar la declaratoria de nulidad absoluta. En este caso el juez deberá examinar las circunstancias y el contenido del contrato de adhesión para determinar si existe o no un desequilibrio. Este examen es sumamente complejo ya que supone un examen crítico de las circunstancias que rodearon la celebración del contrato así como de las prestaciones que corresponden a cada una de las partes. Un buen método de decisión sobre la materia es comparar las cláusulas predispuestas con el derecho dispositivo preestablecido en la legislación civil. El propósito de la comparación es determinar si hay o no una separación injustificada entre ambos regímenes. De cualquier forma, el resultado del examen es incierto y requiere de una elaboración jurisprudencial más concreta.

Ahora bien, si las cláusulas abusivas hacen parte de las condiciones generales de contratación, la revisión del juez no da lugar a tantas incertidumbres. Las diferentes legislaciones sobre la materia contienen una lista de cláusulas abusivas. El control de las cláusulas abusivas incluidas en condiciones generales es en ese sentido prácticamente automático. De cualquier forma, ninguna de las listas es taxativa. Si un consumidor considera que una cláusula es abusiva a pesar de que no está en la lista, el juez deberá aplicar los criterios generales ya señalados. En resumen, si una cláusula abusiva aparece en un contrato de adhesión particular, la validez o nulidad debe resultar de un examen de todo el contrato. Si aparece en las condiciones generales es suficiente con que la cláusula sea de las comprendidas en una lista específica consagrada en la ley.

\section{II.5. Implicaciones para las teorías neokantianas del contrato}

La omnipresencia de las condiciones generales es innegable. Las condiciones generales se usan ampliamente en los sectores financiero, 
bursátil, asegurador y de servicios públicos. Prácticamente todas las empresas formales emplean condiciones generales en sus contratos de trabajo. Lo mismo puede decirse de los contratos de suministro. Para todos los efectos prácticos, el ingreso de un nuevo socio a una persona jurídica presupone la aplicación de condiciones generales bajo la forma de los estatutos de la compañía. Las empresas regidas por convenciones colectivas en realidad emplean condiciones generales para sus nuevos trabajadores. Incluso en la compra de un apartamento los reglamentos de copropiedad hacen las veces de condiciones generales. Pocos campos de la vida social se encuentran a salvo de las reglamentaciones contractuales. Sin querer caricaturizar las teorías neokantianas, parecería que por ninguna parte se encuentran esos dos hombres libres que se dan a sí mismos leyes, derogando el derecho dispositivo. En realidad, es solo una parte la que impone la reglamentación, el nuevo derecho privado, a un número considerable de ciudadanos.

Sostengo entonces que la existencia de condiciones generales de contratación es incompatible con la visión del contrato como herramienta para alcanzar las metas personales sin vulnerar los derechos de los demás. El contrato con condiciones generales es una herramienta pensada para que las empresas, principales agentes sociales, puedan conseguir sus metas particulares, sin que necesariamente se tengan en cuenta las metas de la contraparte. Para que el contrato sometido a condiciones generales pueda funcionar es fundamental que la libertad de configuración del contrato quede abolida en la práctica, siempre en función de los intereses empresariales.

Los defensores de la visión neokantiana del contrato probablemente intentarán alguna de estas respuestas: 1. los contratos con condiciones generales no son contraejemplos para nuestra teoría porque no son contratos; o 2. los contratos con condiciones generales son peligrosos para la libertad pero las herramientas de regulación creadas a lo largo del siglo pasado han permitido corregir estos problemas. La primera respuesta me parece sumamente difícil de sostener. Implicaría reducir el campo de los contratos a los casos que resultan favorables a la teoría liberal kantiana. Sería tanto como negarse a aceptar la 
evidencia disponible. Una posición parecida es la que han asumido algunos doctrinantes de derecho privado que ante la legislación de carácter imperativo prefieren expulsar de la disciplina los contraejemplos (como el derecho laboral, el derecho administrativo, etc.). La segunda respuesta es más interesante. Ciertamente, las legislaciones europeas y latinoamericanas han intentado proteger a la sociedad de los abusos asociados por las condiciones generales. La regla de la incorporación y el régimen de control de las cláusulas abusivas son claros ejemplos en ese sentido. Sin embargo, la regla de incorporación solo sirve para minimizar el impacto de la falta de tratos preliminares en la contratación masiva. El cliente recibe un anexo que contiene las condiciones generales para que al menos se entere del contenido del contrato, pues de lo contrario se correría el riesgo de los contratos secretos. De ninguna manera, el sistema de la incorporación revive el contrato de libre discusión tan anhelado por los neokantianos. E1 régimen de las cláusulas abusivas permite eliminar las injusticias más graves pero tampoco restituye la libertad de configuración perdida. Ambas herramientas hacen 'más aceptables' las condiciones pero no reintegran la libertad contractual usurpada a los ciudadanos hace ya tanto tiempo. Lo mismo habría que decir mutatis mutandi de la teoría de las cláusulas sorpresivas, fundada en la teoría de las expectativas razonables.

\section{Las situaciones contractuales de hecho}

En esta sección explicaré qué son las situaciones contractuales de hecho, qué tipos de situaciones existen y cuál es su régimen jurídico. Finalmente, intentaré probar que las situaciones contractuales de hecho suponen una concepción del contrato que no resulta conciliable con la teoría de Hevia y con ninguna otra teoría de tipo kantiano.

\section{III.1. Concepto y clasificación}

La teoría de las relaciones contractuales de hecho hizo su aparición en un contexto histórico muy especial de la historia europea. En 
lo político, el estado de bienestar parecía extenderse por todos los ámbitos de la sociedad. En lo económico, se habían consolidado las grandes empresas estatales de servicios públicos, y en lo social, la despersonalización de las relaciones sociales se había convertido en la regla general. En muchos ámbitos de la vida social resultaba necesario aumentar la velocidad de las transacciones, simplificar los tratos y disminuir los litigios. Los contratos en masa con cláusulas predispuestas y las condiciones generales de contratación facilitaron enormemente esta tarea. Pero incluso estas innovaciones parecieron insuficientes ante las transformaciones del tráfico jurídico. En muchas ocasiones las transacciones comerciales adquirieron un carácter mecánico, automático e impersonal. Piénsese en la persona que aborda un metro tras haber adquirido un boleto en una máquina dispensadora. No solo no negocia las cláusulas del contrato de transporte sino que ni siquiera habla con nadie. Simplemente ingresa en el vagón y toma asiento tranquilamente en un lugar vacío, mientras se dirige confiadamente a su destino. Considérese también una persona que ingresa a un estacionamiento tras haber presionado un botón. El conductor recibe una tarjeta de una máquina dispensadora para luego parquear su auto. Nadie le ha comunicado que ha celebrado un contrato especial, ni siquiera ha sido informado de la existencia de un contrato de adhesión. En ambos casos, el pasajero de metro y el conductor de un auto han celebrado contratos, pese a que no han hablado con nadie e incluso, a pesar de que no estuvo en su voluntad el deseo de obligarse. Ni siquiera la protesta del pasajero o del conductor evitará la formación del contrato. A juicio de muchos civilistas, estas situaciones requieren de una teoría distinta que permite comprender las particularidades de esta nueva realidad social.

Como respuesta a esta problemática, el civilista alemán Günter Haupt (1904-1946), profesor de la Universidad de Leipzig, escribió su célebre artículo Sobre las relaciones contractuales de hecho (1941) ${ }^{7}$. En este texto desarrolló, como su mismo título lo indica, la célebre teoría

7 Haupt, G., "Über faktische Vertragsverhältnisse", en Hattenauer, H, Conceptos fundamentales del derecho civil, Barcelona, Ariel, 1987. 
Teoría del contrato, libertad y determinismo social: la posición incompatibilista

de las relaciones contractuales de hecho (Lehre vom faktischen vertragsschluss). Esta teoría establece que en las sociedades contemporáneas existen relaciones sociales en las que resulta necesario suministrar o recibir prestaciones y servicios de otras personas sin que previamente se haya dado un consentimiento expreso. El contrato se gesta por le relación social de hecho y no por declaraciones de voluntad. Haupt pensaba especialmente en los servicios públicos domiciliarios (acueducto, alcantarillado, recolección de basuras, electricidad, teléfono, etc.). Al respecto escribe:

En la moderna organización de la convivencia, el individuo es el más imperativamente obligado a dar prestaciones o recibirlas sin elegir al otro contratante, o sin poder determinar con él individualmente el contenido del contrato (...). En tal dislocación del estado de cosas, la coincidencia de voluntades de los afectados pierde su importancia constituyente, reconocida en nuestro sistema de leyes civiles. Así, una compañía de tranvías está obligada a transportar a todo el mundo sin que el viajero tenga que concluir un contrato para que se atienda su demanda de transporte (...). A fin de no originar confusión con una terminología rebuscada, quisiera aplicar a todas estas situaciones de hecho la denominación de 'relaciones contractuales de hecho', expresando así que estas no se basan en la conclusión de un contrato, sino únicamente en precedentes factuales. Se diferencian del resto de los contratos civiles en su proceso de gestación y son fundamentalmente idénticos en su existencia.

Poco tiempo después, el jurista alemán Karl Larenz ${ }^{8}$ (1903-1993), profesor de Kiel, propuso la teoría de la conducta social típica (lehre vom sozialtypischen verhalten) como generadora de contratos. Se trata de un planteamiento muy similar al de Haupt, ya que establece que una serie de conductas sociales típicas dan lugar a contratos sin que sea necesario realizar una declaración de voluntad. Al respecto, Larenz escribe:

8 Larenz, K., "Derecho de Obligaciones". Madrid, Revista de derecho privado, 1958, pág. 58. 
El moderno tráfico en masa trae consigo que en algunos casos, de acuerdo con la concepción del tráfico, se asuman deberes, nazcan obligaciones, sin que se emitan declaraciones de voluntad encaminadas a tal fin. En lugar de las declaraciones surge la oferta pública, y de hecho de una prestación y la aceptación de hecho de la prestación, no suponen (a falta de la correspondiente conciencia de declaración) declaraciones de voluntad, pero sí implican una conducta que por su significado social típico tienen los mismos efectos jurídicos que la actuación jurídica negocial.

\section{E inmediatamente explica:}

Tal es, p. ej., el caso de la utilización del tranvía, del autobús, de una balsa o de un vehículo análogo del transporte público. Es ficticio el considerar, como se intentó antes, que la marcha del tranvía encierra una oferta idéntica y continuada para concluir contratos de transporte, cuya aceptación reside en el hecho de tomar el tranvía. El que utiliza el tranvía está, según el criterio del tráfico, obligado al pago del precio del trayecto según la tarifa y tiene derecho a ser transportado de acuerdo con las condiciones de la tarifa, sin tener en cuenta si su intención consistía en emitir una declaración de voluntad de tal contenido, si tiene o no capacidad negocial, e incluso si conoce o no la tarifa. El suponer que concurre, en tales casos, la conclusión de un contrato encuentra, a mi juicio, un obstáculo en el hecho de que quien utiliza un medio cualquiera de transporte público no está desde luego en la situación de aquel a quien se ha hecho una oferta contractual, y que solo ha de pensar si ha de aceptarla, rechazarla o acaso ha de hacer una contraposición. Se encuentra más bien en la situación general de toda persona que toma parte en el tráfico y piensa si ha de hacer uso de un medio de transporte que está al servicio de todos. Si hace uso de ese medio de transporte, entonces en la consecuencia jurídica de su modo de obrar reside el que con ello haya nacido una relación jurídica, un contrato de transporte, y no porque esa consecuencia jurídica se haya querido o declarado, sino porque, de acuerdo con los puntos 
Teoría del contrato, libertad y determinismo social: la posición incompatibilista

de vista generales del tráfico, su conducta esta indudablemente unida a esa consecuencia. No podrá alegar la excepción de que creía que el transporte era gratuito, impugnando así su declaración por error, o la de que es limitadamente capaz y su representante legal no estaba conforme en que utilizase el tranvía. La admisibilidad de tales objeciones no se ajustaría a la esencia de la cuestión, a su significado social típico.

Larenz sigue las ideas de Haupt pero se cuida de no utilizar la expresión 'relación contractual de hecho' por considerarla inconsistente: si una relación es jurídica no puede ser al mismo tiempo de hecho. Por esa razón, emplea la expresión 'conducta social típica' para hacer referencia a situaciones sociales que implican por sí solas la conclusión de un contrato. Nosotros conservaremos ambas expresiones por considerar que reflejan bastante bien las ideas de la teoría.

La teoría de las relaciones contractuales de hecho es una teoría sobre la formación del contrato. Sus defensores sostienen que algunos contratos nacen de la realización de una conducta social típica, sin que sea necesaria una declaración de voluntad. Por 'conducta social típica' debe entenderse una conducta voluntaria, consciente y libre de una persona, que se adecúa a un marco social preestablecido. Por ejemplo, subir a un autobús, ingresar a un vagón del tren, hacer uso de instalaciones eléctricas, etc. Cuando se dice que la conducta es voluntaria, consciente y libre, se quiere recalcar que no es necesaria la capacidad de ejercicio propia de los mayores adultos. Es suficiente con tener la capacidad de actuar de la que también gozan los menores que ya tienen uso de razón. Pero no cualquier conducta libre da lugar a un contrato. Tiene que tratarse de una conducta típica, es decir, de una conducta cuyo significado social esté absolutamente determinado. Así, subir al metro o al autobús implica que la persona tiene la intención de transportarse, aunque en su interior esté pensando otra cosa. En términos de la dogmática alemana tradicional, tales afirmaciones equivalen a sostener que algunos contratos pueden nacer de

9 Ídem, págs. 58-59. 
actos jurídicos típicos (conductas conscientes, voluntarias y libres) y no solamente de negocios jurídicos (declaraciones de voluntad).

Lo interesante es que en este tipo de situaciones, la conducta social típica tiene prelación sobre cualquier declaración de voluntad que se le oponga. Si, por ejemplo, una persona sube al tren y toma asiento, tal hecho implica per se la celebración de un contrato de transporte. Si el pasajero alega que no era su intención celebrar el contrato, sino tan solo ingresar al vagón para tomar unas fotos, tal declaración no valdrá porque prevalece su conducta exteriorizada socialmente sobre su voluntad interior. Con mayor razón, si el pasajero expresa que no está acuerdo con el costo del pasaje o simplemente no lo ha pagado, de todas formas quedará obligado al pago. Ni siquiera podrá alegar error o dolo, quedándole solo la fuerza para exonerarse. Por ejemplo, podrá alegar que fue obligado contra su voluntad a subir al tren de pasajeros, en dicho caso no hay conducta voluntaria y no podría hablarse de contrato.

Las relaciones contractuales de hecho (conductas sociales típicas) pueden clasificarse en cuatro grandes grupos: relaciones contractuales derivadas de deber social de prestación, relaciones contractuales generadas por la inserción en una comunidad organizada, relaciones contractuales nacidas por contacto social y relaciones contractuales nacidas de la interacción con mecanismos automatizados.

Las relaciones derivadas de un deber social de prestación serían aquellas situaciones en las que una persona, natural o jurídica, en lugar de solicitar expresamente la suscripción, hace uso de un servicio público domiciliario (acueducto, electricidad, gas, teléfono, recolección de basuras, etc.). En este caso, la conducta tipificada implica el sometimiento a una relación contractual de suministro, en las condiciones y tarifas preestablecidas por las autoridades. El uso regular del servicio no podría ser interpretado de otra manera incluso a pesar de las protestas o declaraciones contrarias del consumidor. Dado que las condiciones y requisitos del contrato pueden haber sido predispuestas por una sola de las partes, el adherente podrá denunciar la existencia de cláusulas abusivas según las reglas generales sobre la materia. 
Teoría del contrato, libertad y determinismo social: la posición incompatibilista

Las relaciones contractuales generadas por la inserción en una comunidad organizada corresponden a aquellas situaciones en las cuales una persona cumple un rol socialmente reconocido en el interior de un grupo humano. Es el caso de las personas que empiezan a trabajar junto a otras en la realización de una empresa o que trabajan bajo la dirección de otras, sin que sea necesario que entre ellas haya existido la intención expresa de crear una sociedad legalmente constituida o de celebrar un contrato de trabajo estable. Esta situación abarca también aquellos casos en los cuales se ha declarado la nulidad de un contrato de sociedad o de trabajo. El efecto ex nunc de las sentencias de nulidad implica el reconocimiento pleno por parte del ordenamiento jurídico de la relación fáctica establecida por las partes. En cualquier caso, las sociedades de hecho o los contratos de trabajo de hecho son los casos más citados.

Las relaciones contractuales nacidas por simple contacto social consisten en situaciones de interacción humana que si bien no están expresamente regidas por un contrato, están reglamentadas como si lo estuviesen. Hay dos casos: situaciones que no son claramente contractuales, como el transporte benévolo o los tratos preliminares y los contratos declarados nulos solo hacia el futuro, como el arrendamiento o el suministro de hecho. El transporte benévolo acontece cuando el conductor de un vehículo hace el favor de llevar o acercar a una persona a cierto destino y no cobra ninguna tarifa por el viaje. Para los defensores de la teoría, pese a que ninguna de las partes ha tenido la intención de contratar, de todas formas se genera un contrato gratuito y surgen obligaciones especiales para ambas partes. El conductor debe mirar por la seguridad de su acompañante y este, a su turno, no debe impedir el buen desarrollo del viaje. En los tratos preliminares, los participantes de una negociación contractual deben cumplir con varios deberes como la información, la reserva, la seguridad, etc. Por esa razón, el simple contacto social generaría obligaciones de carácter contractual. Pero el caso más sobresaliente de contacto social es el de los contratos nulos de tracto sucesivo: suministro, renta vitalicia, arrendamiento, entre otros. Dado que la nulidad no produce efectos retroactivos, el ordenamiento jurídico reconoce 
que las partes estuvieron obligadas en el pasado, pese a las irregularidades en la formación del contrato.

Las relaciones contractuales nacidas por interacción con mecanismos automatizados son las más frecuentes en nuestro tiempo. Se trata de situaciones en las cuales una persona acciona voluntariamente una máquina que ha sido predispuesta por su dueño para brindar un servicio. Es el caso de las dispensadoras de productos (alimentos, bebidas, tabaco, periódicos) o servicios (cambio de divisas, boletos de tren o autobús, etc.). También son ejemplos las cabinas telefónicas, los parqueaderos automatizados, entre muchos otros. La interacción supone que el usuario, valiéndose de ciertas instrucciones muy simples, active los dispositivos de suministro o haga uso del servicio. Los contratos que nacen de estas relaciones son, por lo general, compraventas, suministros o prestaciones de servicios. Hay una relación contractual porque se sobreentiende que la predisposición de las máquinas en cuestión tiene como propósito directo la realización de una transacción económica.

La teoría de las relaciones contractuales de hecho ha tenido una amplia recepción en el Derecho civil italiano. En especial, desde que Lorenzo Campagna presentó la teoría en su libro I 'negozi di attuazioni' e la manifestazione dell'intento negoziale ${ }^{10}$ (1958). El trabajo de Campagna se centra en demostrar que las categorías alemanas de acto y negocio jurídico son difusas y no siempre se pueden separar. El caso típico de situación híbrida se daría en las relaciones contractuales de hecho, que el autor prefiere denominar con la expresión negocios jurídicos de actuación. Los negocios de actuación son actos jurídicos que por su tipicidad social cumplen la misma función que las declaraciones de voluntad (negocios jurídicos). La teoría italiana de los negocios jurídicos de actuación no plantea grandes diferencias que la separen de la doctrina alemana. Hay un punto que sí reviste particular interés. Me refiero a la forma mucho más general como suelen clasificar las situaciones. Los negocios de actuación serían regulares e irregulares.

${ }^{10}$ Campagna, L., I 'negozi di attuazioni' e la manifestazione dell'intento negoziale, Milán, 1958. 
Teoría del contrato, libertad y determinismo social: la posición incompatibilista

Los negocios de actuación irregulares abarcarían las hipótesis de contratos nulos de tracto sucesivo (contratos de trabajo de hecho, sociedades de hecho, etc.). Los negocios de actuación regulares se subdividen en dos: negocios regulares unipersonales y negocios regulares pluripersonales. Ejemplos de negocios de actuación unipersonales serían la ocupación, la derelicción, la destrucción del testamento ológrafo, el retiro del testamento secreto, la transformación de la cosa legada, el pago de la deuda prescrita, el cumplimiento del contrato anulable, entre otros. Ejemplos de negocios regulares pluripersonales serían las aceptaciones a través de conductas tácitas, como sucede con la tácita reconducción, el mandato tácito y, de manera más general, con la aceptación mediante ejecución directa del contrato ofrecido.

La teoría italiana de los negocios jurídicos de actuación es importante porque le permitió a los civilistas darse cuenta de que las relaciones contractuales de hecho no constituían situaciones aisladas o marginales como inicialmente lo habían supuesto los doctrinantes alemanes. El caso de los negocios de actuación unipersonales ilustra este punto. En los países en los que es válido el testamento ológrafo (hecho a mano), la destrucción del documento equivale a una retractación expresa por parte del testador. Igualmente, el testador que transforma la naturaleza de la cosa legada (funde el reloj o separa los materiales de un anillo) se retracta de su disposición a través de su conducta voluntaria. En el ámbito de los derechos reales, quien ocupa un bien sin dueño o que ha sido abandonado expresa su intención de adquirirlo e, inversamente, quien abandona un bien voluntariamente expresa su propósito de renunciar a su dominio.

\section{III.2. Régimen jurídico}

Expuesta la teoría de las relaciones contractuales de hecho nos resta por examinar sus implicaciones prácticas. De acuerdo con los defensores de esta teoría, en las relaciones contractuales de hecho el contrato no se forma a través de un intercambio de declaraciones de voluntad, es decir, a través de una oferta seguida de una aceptación. La mera conducta social típica es suficiente para que la ley impute 
la generación de una relación jurídica contractual. En consecuencia, consideran estos autores, no es necesario que las personas que realizan los actos tengan capacidad legal de ejercicio (unánimemente concedida a partir de la mayoría de edad). Esto quiere decir que únicamente se exige la capacidad natural, es decir, la edad suficiente para realizar acciones voluntarias y racionales. Esta capacidad natural es la que tienen los infantes que ya gozan del uso de razón y que la mayoría de los sistemas jurídicos conceden a partir de los siete años. De suerte que, por ejemplo, un niño de ocho años que accione una máquina dispensadora de alimentos estaría celebrando una compraventa válida, sin que sea necesario acudir a la ficción de una autorización tácita de su representante legal. En igual situación estaría el menor de once años que ha adquirido un boleto de tren en una taquilla automática y que luego ha subido al vagón de pasajeros.

Como la formación de las relaciones contractuales de hecho nace de conductas sociales típicas, sin necesidad de un intercambio de declaraciones, no es predicable de estas situaciones ni el error ni el dolo. En efecto, quien hace uso de un servicio público o quien interactúa con un mecanismo automatizado no puede argumentar que desconocía lo que estaba haciendo ni, mucho menos, que fue engañado por la contraparte. El hecho de que estemos ante conductas sociales típicas permite inferir que quien las ejecute sabe perfectamente las implicaciones de su actividad: emplear los servicios públicos de una casa, subir a un tren, marcar un número telefónico en una cabina pública, introducir una moneda en una máquina dispensadora, etc. El único vicio que podría alegarse en contra del surgimiento del contrato es la fuerza. Una persona que ha sido secuestrada y luego transportada en un tren no tiene que pagar la tarifa. En estos casos no hay conducta voluntaria, negocio de actuación y, por tanto, tampoco hay contrato. En resumen, las relaciones contractuales de hecho no deben cumplir todos los requisitos de validez que son propios de las declaraciones de voluntad. Es apenas suficiente con que exista una conducta voluntaria, consciente y libre.

Además, hay que señalar que el significado social de la conducta típica prevalece incluso por encima de las declaraciones de voluntad 
del agente. En otras palabras, si una persona realiza una conducta social generadora de una relación contractual de hecho, el contrato nacerá incluso en contra de la protesta del agente mismo. Un caso citado frecuentemente por los defensores de la teoría es el de un ciudadano alemán que decidió parquear su automóvil en un lugar público. Las autoridades locales habían entregado la concesión del lugar a un particular para que este se encargara de administrarlo y cobrara una tarifa de parqueo. El ciudadano alemán dejó en varias ocasiones su auto en el sitio pero haciendo la advertencia de que no aceptaba celebrar contrato alguno y mucho menos pagar la tarifa establecida. A pesar de la protesta, los tribunales alemanes afirmaron que se había producido una relación contractual de hecho que obligaba al ciudadano a pagar la tarifa previamente fijada por las autoridades locales.

Por último, en las relaciones contractuales de hecho rige fundamentalmente el derecho dispositivo, es decir, las normas de carácter subsidiario que el legislador ha establecido para los contratos que no han sido completamente configurados por las partes. No podría ser de otra manera ya que estamos ante contratos que se han formado por la conducta de las partes, sin intercambio informacional alguno. Así, en caso de realizarse la conducta social típica de un contrato de suministro de servicios públicos domiciliarios, aplicará el régimen legal previsto para esta tipología. Dado que en este tipo de contratos siempre se aplica el derecho dispositivo, ya que nunca puede ser derogado por acuerdos entre particulares, se sigue que el derecho dispositivo se torna en una especie de derecho imperativo que reduce notablemente la libertad de configuración contractual. De hecho, solo habría una forma de derogar el derecho dispositivo: cuando una empresa predispone condiciones generales de contratación. En caso de que una de las partes emplee condiciones generales de contratación, el requisito de la incorporación tendrá que cumplirse por medio de carteles o avisos ubicados en lugares públicos. Sin el cumplimiento de este requisito las condiciones generales quedarían por fuera del negocio de actuación. No hay duda de que una situación contractual de hecho reglamentada por medio de condiciones generales es todo lo contrario de lo 
que las concepciones neokantianas del contrato han imaginado en sus paraísos libertarios.

\section{III.3. Implicaciones para las teorías neokantianas del contrato}

$\mathrm{Al}$ igual que las condiciones generales, las situaciones contractuales de hecho son una realidad social innegable. Encontramos situaciones contractuales en contextos tan disímiles como los servicios públicos domiciliarios (agua, luz, teléfono, celular, acueducto, alcantarillado, gas, servicios de internet, televisión prepaga), el transporte público (metro, tren, bus, taxi), los contratos celebrados a través de máquinas automatizadas (autoservicios, máquinas dispensadoras de productos y servicios) y operaciones de comercio electrónico, entre muchos otros. Pero quizás, el mejor caso de situación contractual de hecho es aquel en que se encuentran los trabajadores informales que luchan porque su situación de subordinación sea reconocida por las empresas e implique la afiliación obligatoria a los sistemas de seguridad social y protección de la salud.

Sostengo entonces que la existencia de situaciones contractuales de hecho es incompatible con la visión del contrato como herramienta para alcanzar las metas personales sin vulnerar los derechos de los demás. El contrato entendido como situación contractual de hecho, como negocio de actuación, supone que la conducta social está tipificada de tal forma que no cabe deducir de ciertas conductas nada más que el deseo de obligarse. En este marco, la conducta social típica no puede interpretarse como una propuesta de diálogo sobre los términos de un servicio o producto ya que no hay espacio para la discusión. Actuar es ya contratar, es tomar la decisión de contratar, sin el más mínimo espacio para la libertad de no contratar. Si la libertad de no contratar es inexistente, mucho menos puede haber libertad contractual. Y sin embargo, hay contrato de contenido imperativo desde la primera palabra hasta la última, pero contrato al fin y al cabo. Contrato sin ninguna de las características que los neokantianos le atribuyen: como herramienta para conseguir las metas individuales sin contrariar las metas ajenas. En este ámbito no existe interacción 
Teoría del contrato, libertad y determinismo social: la posición incompatibilista

de individuos razonables que dialogan, negocian, ceden un punto a cambio de otro, hasta construir una esfera justa de libertades. Lo único que hay es el efecto jurídico inmediato, la obligación imperativa a la que no es posible sustraerse.

Con seguridad, los defensores de las teorías neokantianas del contrato argumentarán que: 1 . Las situaciones contractuales de hecho no son verdaderos contratos; o 2. Las situaciones contractuales de hecho están reguladas de tal forma que no atentan verdaderamente contra la libertad. La primera opción, al igual que en el caso de las condiciones generales, no resulta muy atractiva como respuesta teórica a las objeciones. Afirmar que las situaciones contractuales de hecho no son verdaderos contratos es tanto como negar la evidencia desfavorable. La segunda opción es la más interesante pero la considero igualmente falsa. Sin duda, para que un contrato de hecho se forme es necesario que preexista una conducta libre y consciente, requisito predicable de una persona normal, mayor de por lo menos ocho años. También es preciso reconocer que si una persona es sometida a violencia física o moral puede solicitar la anulación del contrato. Hay pues un reducto de libertad en las situaciones contractuales, reducto que podemos denominar 'libertad mínima'. Sin embargo, estas condiciones mínimas de libertad requeridas para las situaciones contractuales de hecho no reviven la verdadera libertad contractual, cuyo contenido pretende ser una verdadera autorregulación de la autonomía privada. Es lo que podemos llamar 'libertad máxima'. Nada hay en las situaciones contractuales de hecho que permita pensar en la libertad contractual máxima, constituida por la libertad de conclusión y la libertad de configuración. Tan cierta es esta conclusión que no cabe pensar aquí en la posibilidad de anulación del contrato por error, pues el ciudadano no recibe ningún margen de libertad para regular su conducta, para perseguir sus metas individuales como quisiera.

En resumen, se ha intentado demostrar aquí que los cambios históricos sociales producidos en el último siglo han afectado profundamente la noción tradicional de contrato. La existencia de condiciones generales de contratación y la aparición de las situaciones contractuales de hecho han recortado gravemente las libertades contractuales 
de conclusión y configuración. Hay una incompatibilidad irreconciliable entre las nuevas instituciones presentadas y la concepción tradicional del contrato. En efecto, el contrato de nuestro tiempo continúa siendo un importante sistema de coordinación de la acción individual y colectiva pero no es necesariamente un espacio de autonomía privada. Si estoy en lo cierto, las reconstrucciones kantianas o neokantianas de esta institución deberán ser abandonadas, o al menos, sometidas a una revisión profunda.

\section{Bibliografía}

Campagna, L., I 'negozi di attuazioni' e la manifestazione dell'intento negoziale, Milán, Giuffré, 1958.

Código Civil Alemán.

Haupt, G., "Über faktische Vertragsverhältnisse", en Hattenauer, H., Conceptos fundamentales del derecho civil, Barcelona, Ariel, 1987.

Josserand, L., Curso de derecho positivo civil francés. Buenos Aires, Bosch, 1950.

Larenz, K., "Derecho de Obligaciones". Revista de derecho privado, Madrid, 1958.

Saleilles, R., De la déclaration de volonté, Paris, Librarie Générale du Droit et de Jurisprudence, 1929. Art. 133. 89 y 90. 